\title{
Determining the ontogenetic variation of lower cheek teeth occlusal surface patterns in lagomorphs using micro-ct technology
}

\author{
Chiara Angelone, Julia A. Schultz, and Margarita A. Erbajeva
}

\begin{abstract}
Micro CT-scanning has been performed on the lower jaws of some selected lagomorph taxa in order to reconstruct unequivocally their controversial ontogenetic development. The analyses were concentrated on the development of p3, and on the sequences of lobe connections and on the sequence of appearance/disappearance of flexids/fossettes of p4-m2.

This is the first time that this approach has been applied to lagomorphs and opens promising perspectives especially for the taxonomy and phylogeny of this complex order.
\end{abstract}

Chiara Angelone. Institut Català de Paleontologia, Universitat Autònoma de Barcelona, 08193 Cerdanyola del Vallès, Barcelona, Spain, chiara.angelone@icp.cat

Julia A. Schultz. Steinmann-Institut für Geologie, Mineralogie und Paläontologie, Universität Bonn, Nussallee 3, 53115 Bonn, Germany, schultzj@uni-bonn.de

Margarita A. Erbajeva. Geological Institute, Siberian Branch, Russian Academy of Sciences, Ulan-Ude, Russia 670047, erbajeva@gin.bscnet.ru

Keywords: micro-ct; Lagomorpha; ontogeny; lower teeth

\section{INTRODUCTION}

The occlusal surface of lagomorph cheek teeth, especially stem lagomorphs, drastically varies with ontogeny. Until now ontogenetic variation has usually been inferred by extrapolation from specimens in different wear stages (e.g., Tobien, 1974, pp. 110-122; López Martínez, 1989, p. 189), with the implicit a priori assumption that these stages pertained to the same taxon. This approach has led to taxonomic misinterpretation and thus incorrect phylogenetic reconstructions.

Micro CT-scanning is a non-destructive method of obtaining $x$-ray images of objects and the reconstructed image stack can be used for virtual cutting of the object at different levels. In the case of high-crowned teeth this method gives insight in the variation of tooth crown pattern by virtually imitating different wear stages/levels. 
Using Micro CT-technology we attempted to reconstruct the ontogenetic development of the lower cheek teeth of some lagomorph genera of different families, ages and continents. The aim of this study is to describe the ontogenic development of the lower tooth row of different lagomorph genera, which previously were only inferred from the occusal surface of different wear stages by different authors. This is the first time that CT-scanning is used for this purpose in lagomorphs.

Once integrated in the analysis of other lagomorph genera, our results will provide (1) a new approach for reconstructing the relationships among lagomorph genera; and (2) tools for investigating the differences in the patterns of evolution between different lineages as well as between different continents.

\section{MATERIAL AND METHODS}

In order to investigate the un-erupted parts of the hypsodont teeth, jaws were scanned using the Micro-CT scanner v/tome/xs (GE sensing Inspection technologies $\mathrm{GmbH}$ phoenix/X-ray) housed in the Steinmann-Institut für Geologie, Mineralogie und Paläontologie, Rheinische Friedrich-Wilhelms Universität Bonn, Germany. The scans were carried out with the $240 \mathrm{kV}$ tube of the Phoenix|x-ray v|tome|x s 240 (GE Electronics) with varying settings (see below). The Micro-CT device produces isotropic voxels, meaning the same thickness in each direction. As a result the resolution of the scan is equal with the slice thickness. The CT-data were processed with the reconstruction software datos $x$ res of the device and VGStudioMax and Avizo 6.1 in order to visualize virtual slices and 3D surfaces. In addition single tooth positions were reconstructed with datos $\mathrm{x}$ res software in "resolution 2" mode in order to virtually halve the resolution and as a result achieve higher resolved scans. Therefore the software automatically interpolates between the grey values of two adjacent voxels and calculates the virtual grey value for an additional voxel between them using the integrated algorithm.

In this preliminary study we decided to analyse the lower cheek teeth, because enamel patterns and structures are simpler than in upper cheek teeth. In addition, lower cheek teeth in contrast to upper ones do not undergo a patent nonparallel abrasion during ontogeny. Rather, the wear plane of upper teeth follows a very complex pattern, especially in archaic lagomorphs (Bair, 2007). The specimens have been virtually sectioned at several heights parallel to a plane approximating the occlusal surface (Figure 1).

We chose taxa of different families and from different continents ("Amphilagus", stem lagomorph, 25-22 Ma, Europe; Desmatolagus, stem

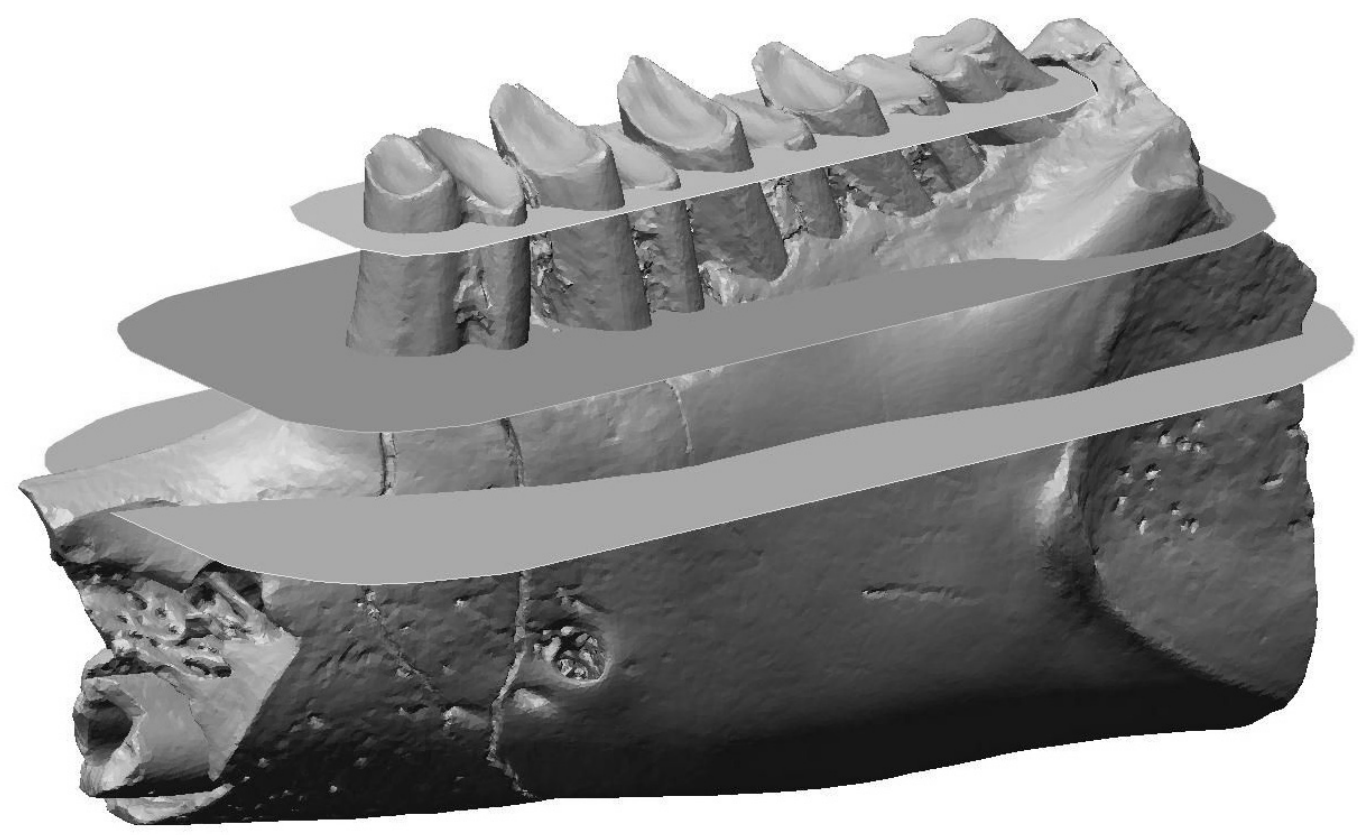

FIGURE 1. Example of how the selected Micro-CT scanned specimens were virtually sectioned at several heights parallel to a plane approximating the occlusal surface. 
TABLE 1. Sequences of appearance/development of p3-m2 of lobe connections, and of appearance/disappearance of flexids/fossettes in the studied specimens.

\begin{tabular}{|c|c|c|c|c|c|}
\hline & & "Amphilagus" antiquus & Piezodus branssatensis & $\begin{array}{l}\text { Desmatolagus } \\
\text { cf. youngi }\end{array}$ & Palaeolagus sp. \\
\hline p3 & $\begin{array}{l}\text { development } \\
\text { posterior flexids/ } \\
\text { fossettes }\end{array}$ & $\begin{array}{c}\text { deep hypoflexid --> } \\
\text { hypoflexid+mesofossettid --> } \\
\text { shallowing of hypoflexid }+ \\
\text { disappearance of mesoflexid }\end{array}$ & $\begin{array}{l}\text { hypoflexid + mesoflexid --> } \\
\text { hypoflexid + mesofossettid--> } \\
\text { shallowing of hypoflexid + } \\
\text { disappearance of mesoflexid }\end{array}$ & $\begin{array}{l}\text { shallowing of } \\
\text { hypoflexid }\end{array}$ & $\begin{array}{c}\text { hypoflexid + mesoflexid --> } \\
\text { hypoflexid }+ \text { mesofossettid --> } \\
\text { hypoflexid alone }\end{array}$ \\
\hline \multirow[t]{3}{*}{$\mathrm{p} 4-\mathrm{m} 2$} & $\begin{array}{l}\text { trigonid-talonid } \\
\text { connection }\end{array}$ & m2-m1-p4 & m2-m1-p4 & m2-m1-p4 & m1-m2-p4 \\
\hline & $\begin{array}{l}\text { hypoconulid --> } \\
\text { fossette }\end{array}$ & m1-m2-p4 & m1-p4-m2 & - & - \\
\hline & $\begin{array}{c}\text { fossette } \\
\text { disappearance }\end{array}$ & m1-m2-p4 & m1-m2-p4 & - & - \\
\hline
\end{tabular}

lagomorph, $\sim 45-25 \mathrm{Ma}$ in Asia; Palaeolagus, leporid, 38-26 Ma, North America; Piezodus, ochotonid, 24-20 Ma, Europe; age data from López Martínez, 2008) in order to have a wide range of different ontogenetic developmental stages of the selected characters of the dental occlusal surface, such as trigonid-talonid connections in p3-m2 and flexids/fossettes in p4-m2. Nomenclature of features of teeth occlusal surfaces follows Palacios and López Martínez (1980).

The analyzed specimens are (see also Koenigswald et al., 2010):

"Amphilagus" antiquus, Coderet-Branssat, France, uppermost Oligocene MP 30 (NMB - BST 45-3c [CT scan resolution $=0.0154 \mathrm{~mm}$, virtual resolution $=0.0077 \mathrm{~mm}$, settings $=$ $140 \mathrm{kV}$ and $110 \mathrm{~mA}$;

Desmatolagus cf. youngi (quite senile individual), Tatal Gol D/0, Mongolia, Late Oligocene (NHMW_2011-0209-0003) [CT scan resolution $=0.025851 \mathrm{~mm}$, settings $=150 \mathrm{kV}$ and $130 \mathrm{~mA}$;

Palaeolagus sp., Toadstool Park Area, Nebraska, Late Eocene/Early Oligocene (col. K. Hirsch; STIPB - KOE 668) [CT resolution = $0.02102 \mathrm{~mm}$, settings $=150 \mathrm{kV}$ and 130 $\mathrm{mA}]$;

Piezodus branssatensis, Coderet-Branssat, France, uppermost Oligocene MP 30 (NMB - BST 3899 [CT scan resolution = $0.02264 \mathrm{~mm}, \mathrm{p} 4$ and $\mathrm{m} 1$ virtual resolution $=0.01134 \mathrm{~mm}$, settings $130 \mathrm{kV}$ and 110 $\mathrm{mA}]$;

Piezodus branssatensis (juvenile individual), Coderet-Branssat, France, uppermost Oligocene MP 30 (NMB - Cod 273) [CT scan resolution $=0.0147 \mathrm{~mm}$, settings $=150 \mathrm{kV}$ and $140 \mathrm{~mA}$ ].
Abbreviations: NHMW- Naturhistorisches Museum Wien; NMB- Naturhistorisches Museum Basel; STIPB- Steinmann-Institut für Geologie, Mineralogie und Paläontologie Bonn.

\section{RESULTS}

In the virtual Micro CT-scan "sections" of the studied genera we observed different timings in the appearance/development in p3-m2 of lobes connections, and in the appearance/disappearance of flexids/fossettes (sequences are summarized in Table 1).

\section{Development of $\mathrm{p} 3$}

Being the most important tooth for diagnosis at the species level, the reconstruction of ontogenetic development of the p3 is of primary importance for the phylogeny of lagomorphs, especially rooted ones, in order to avoid taxonomic mistakes.

Controversies and errors in the taxonomy of European stem lagomorphs have already been highlighted in literature, as for example the long debated synonymy between Titanomys visenoviensis and "Amphilagus" antiquus (Álvarez-Sierra et al., 1990 and references therein) or the different genera lumped in "Amphilagus" (cf. Angelone, 2009).

The ontogenetic development of the p3 of "Amphilagus" antiquus is shown in Animation 1. The occlusal surface of the p3 of the analyzed specimen is C-shaped, with a single labial flexid (hypoflexid) and a lingually directed hypoconulid (Figure 2.1). With wear the hypoconulid shallows up until disappearing, whereas the hypoflexid is interrupted by a central connection that develops between trigonid and talonid; such a connection determines the formation of a mesofossettid (Figure 2.2-3). These steps correspond to the reconstruction of the ontogenetic development of the p3 in "Amphilagus" antiquus based on the relatively 


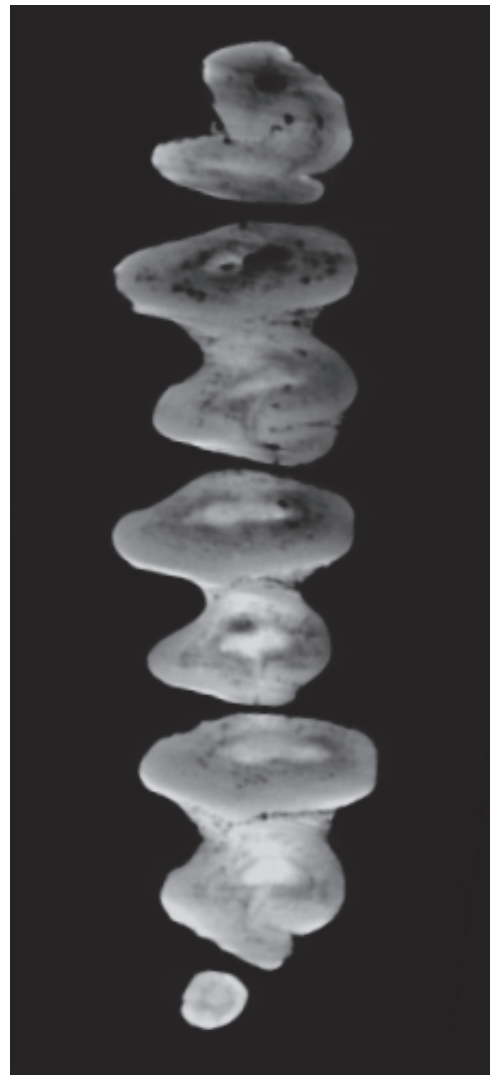

ANIMATION 1. Virtual sectioning of the lower jaw of "Amphilagus" antiquus shows the ontogenetic development of lower cheek teeth.

palaeo-electronica.org/content/2014/659-tooth-ontogeny-from-ct rich collections from Coderet (MP 30) (López Martínez, 1989, p. 189, figure 50 B 3-4-5). Our results show that further wear of the tooth leads to the simultaneous shallowing up of the hypoflexid and disappearance of the mesofossettid (Figure 2.3-4), in contrast with the morphotype of a senile stage as predicted by López Martínez (1989, p. 189, figure 50 B 6) and Tobien (1974, p. 122, figure $14 \mathrm{u}$ ), in which the hypoflexid merges with the mesofossettid again forming a deep, unique flexid. In very late stages of wear a very shallow lingual flexid seems to appear in the trigonid (Figure 2.45 ), but this evidence should be verified by further analyses.

The p3 of Desmatolagus cf. youngi is quite simple, a triangle with a labial concavity (hypoflexid) that shallows up with advanced wear (Figure 3.2-3; Animation 2).

An early central connection between trigonid and talonid is characteristic for a p3 of Palaeolagus (Figure 4.1). With increasing wear, an enamel wall closes the lingual flexid (mesoflexid) forming a mesofossettid (Figure 4.2-3). Eventually the mesofossettid becomes smaller until disappearing, whereas the hypoflexid does not significantly shallow up (Figure 4.4). Our specimen of Palaeolagus has attained a medium stage of wear, thus the hypoconulid, present in less worn specimens, has already disappeared.
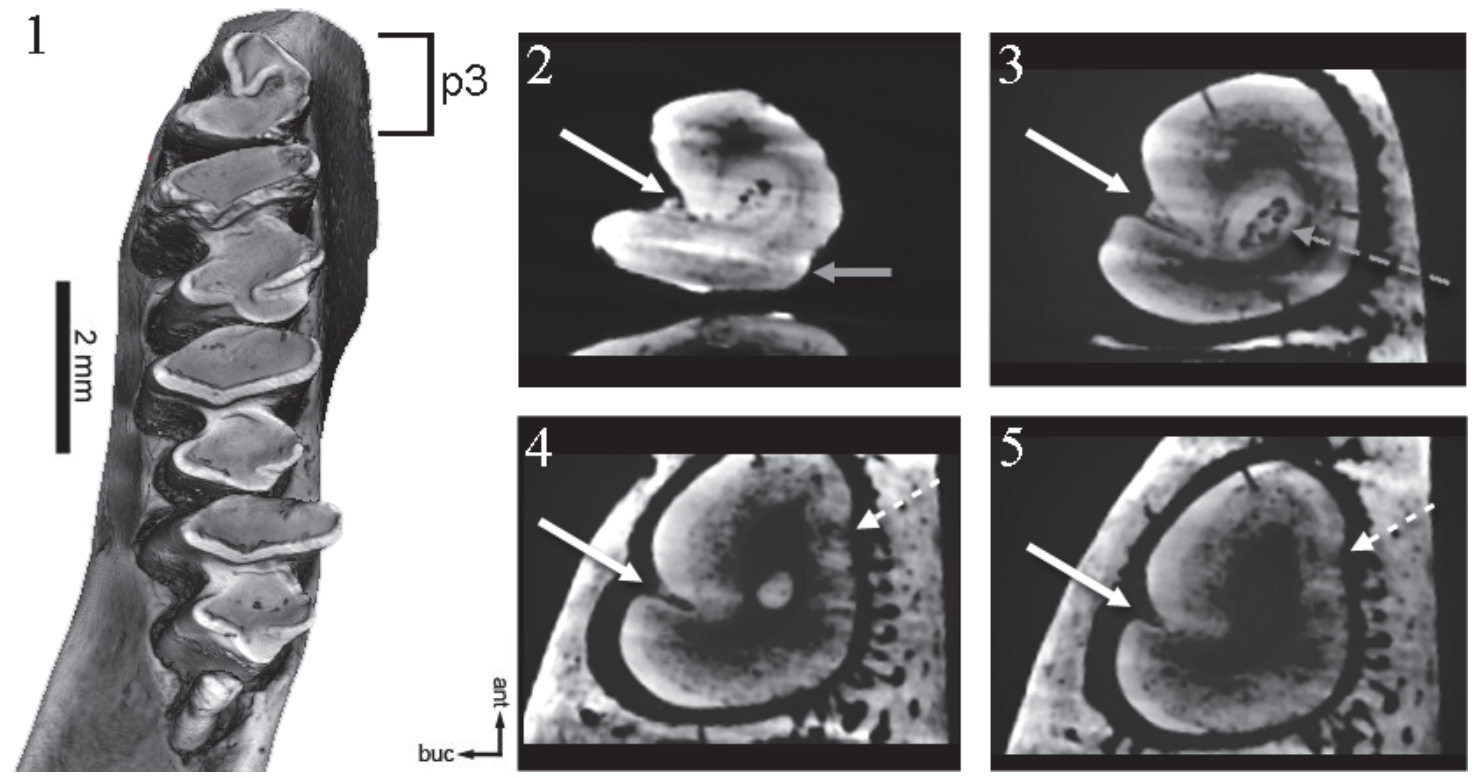

FIGURE 2. Virtual sections of the ontogenetic development of the p3 of "Amphilagus" antiquus. (1) Occlusal surface. The hypoconulid shallows up (2) and a central connection interrupts the hypoflexid forming a mesofossettid (3). Both hypoflexid and mesofossettid progressively disappear in further stages of wear $(4,5)$. White arrow: hypoflexid; grey arrow: hypoconulid; dotted white arrow: lingual flexid; dotted white arrow: mesofossettid. 

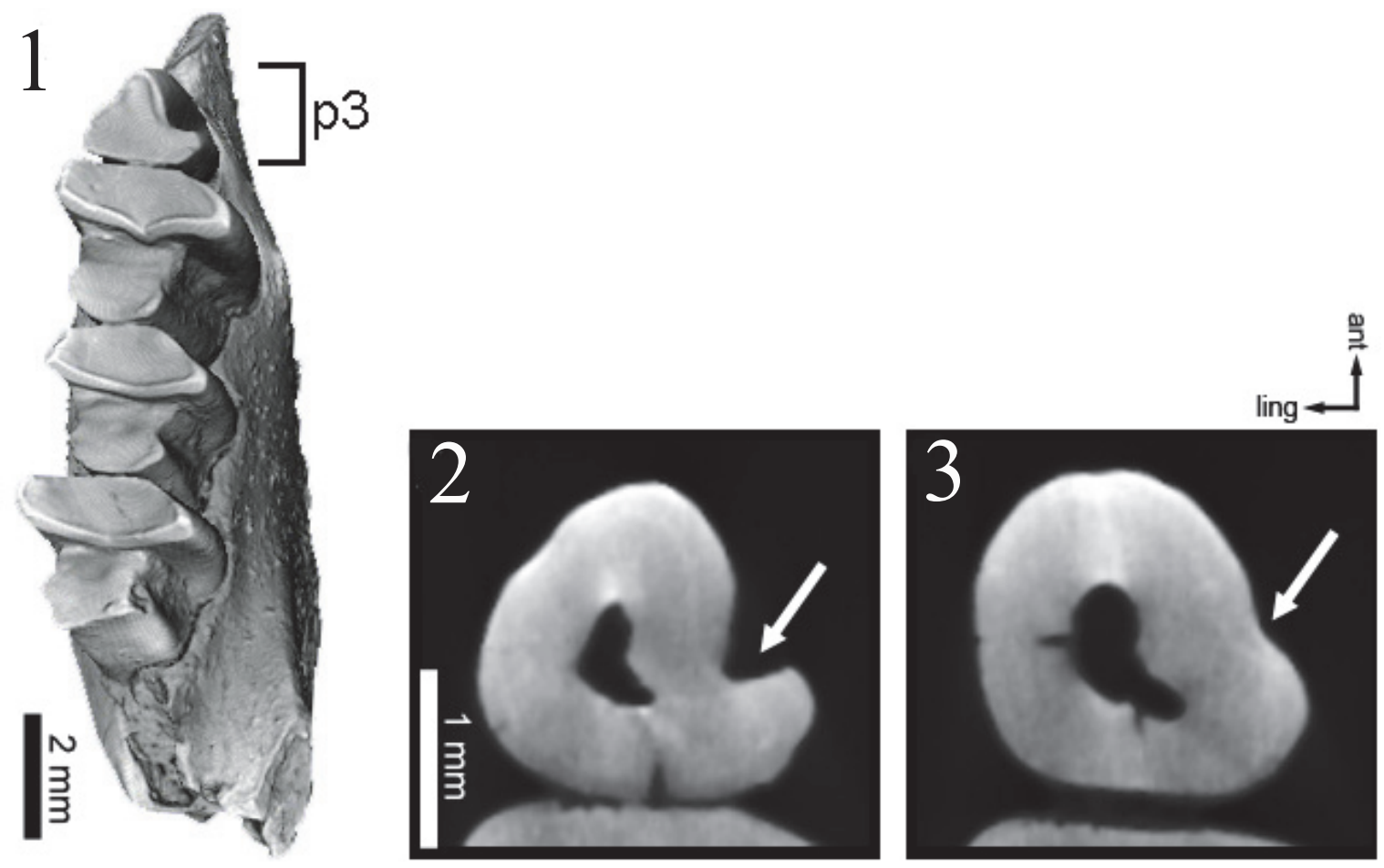

FIGURE 3. Virtual sections of the ontogenetic development of the p3 of Desmatolagus cf. youngi. (1) Occlusal surface. The hypoflexid (white arrow) progressively shallows up $(2,3)$.

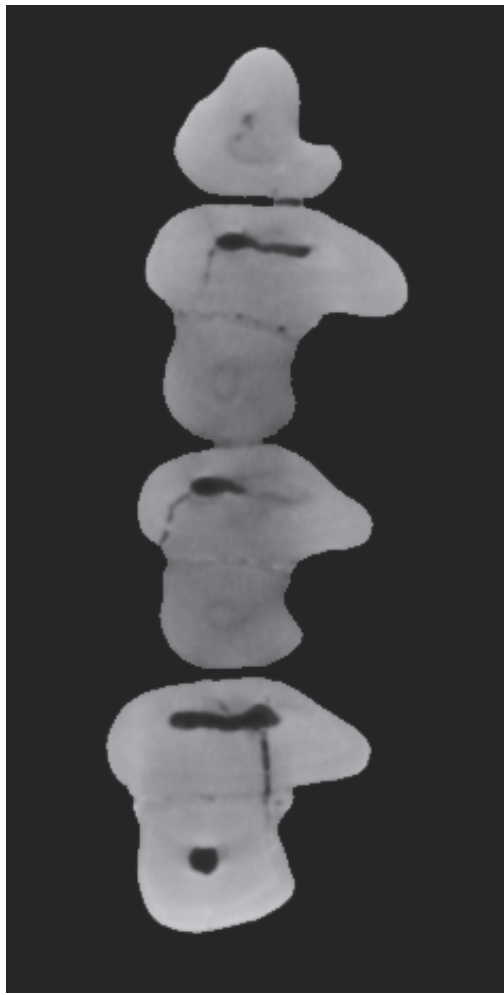

ANIMATION 2. Virtual sectioning of the lower jaw of Desmatolagus cf. youngi shows the ontogenetic development of lower cheek teeth.

palaeo-electronica.org/content/2014/659-tooth-ontogeny-from-ct
The p3 of Piezodus is not a simple hourglass as in Palaeolagus, but it shows an anteroconid and usually a hypoconulid (see Tobien, 1975, p. 132, figures 31-35). We investigated two specimens of lower jaws of Piezodus: a very young one, still with deciduous teeth, and an adult (but not senile) specimen. Thus, we could virtually combine the wear patterns of the two samples to obtain a longer ontogenetic sequence.

Under the dp3 of the younger specimen the virtual Micro-CT virtual section shows a peculiar unworn p3, completely lacking the anteroconid along its shaft (Figures 5.1, 6.2); also the hypoconulid seems absent. From literature only one example of a p3 of a quite senile individual of Piezodus is reported (our age estimation is based on the fact that it shows an enamel connection between trigonid and talonid on the lingual border), which bears a still unworn anteroconid (cf. Tobien, 1975 , p. 135 , figure 38 ). Our analysis shows that the general shape of the p3 does not substantially change with wear in the juvenile specimen of Piezodus (Figure 6.2-3).

In contrast, in the adult specimen of Piezodus the anteroconid is already present (Figure 6.4), and we were unable to detect the exact moment in which the anteroconid is developed. However, we could observe the anteroconid merging with the tri- 


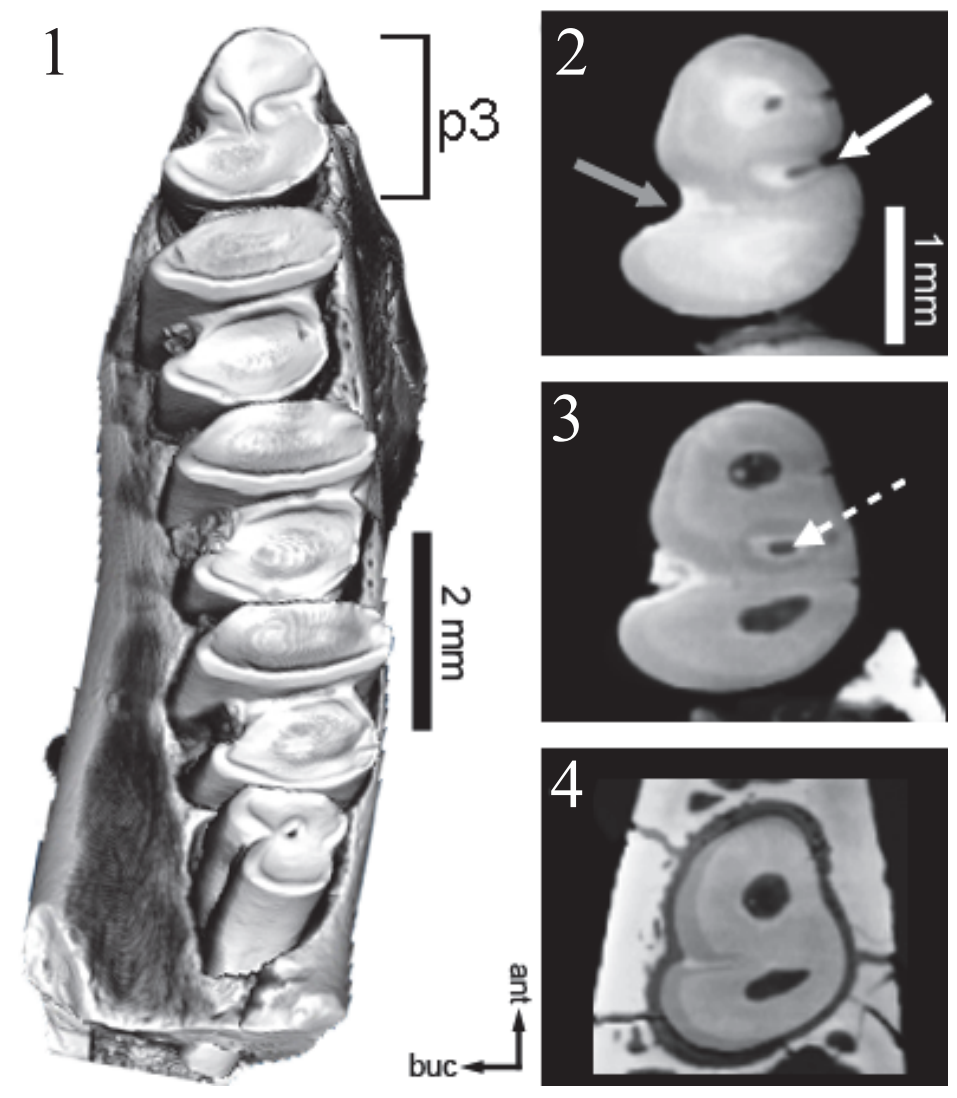

FIGURE 4. Virtual sections of the ontogenetic development of the p3 of Palaeolagus sp. (a) Occlusal surface. Beginning with an hourglass shape $(1,2)$, an additional lingual connection between trigonid and talonid forms a mesofossettid (3); the hypoflexid does not substantially shallow up (4). White arrow: mesoflexid; grey arrow: hypoflexid; dotted white arrow: mesofossettid.

gonid connecting on the lingual side (Figure 6.5) just before trigonid and talonid get lingually connected forming a mesofossettid (Figure 6.6). With very advanced wear the mesofossettid disappears and the hypoflexid shallows up (Figure 6.7). This latter stage of wear is not likely to be reached during lifetime. Another interesting feature we observed is the appearance of the roots, absent in the teeth of the juvenile specimen of Piezodus but present in the older one (Figure 5.2).

\section{p4-m2 Trigonid-Talonid Connections}

In modern leporids lower check teeth are characterized by a thin lingual connection between trigonid and talonid. Such a connection is absent in ochotonids and stem lagomorphs and appears only at extremely advanced stages of wear, or stages of wear that are never attained during the normal wear attained during lifetime.

The primitive leporid Palaeolagus does not show a trigonid-talonid connection in early wear stages (Figure 7.1). During wear the trigonid-tal- onid connection appears following the sequence m1-m2-p4 (Figure 7.2-3; Animation 3).

In Desmatolagus the wear causes the originally separated trigonid and talonid (Figure 8.1) to be lingually connected, but in a different sequence when compared to Palaeolagus: m2-m1-p4 (Figure 8.2-4; Animations 2, 3).

"Amphilagus" and Piezodus follow the same pattern as found in Desmatolagus: m2-m1-p4 (Figures 9, 10; Animations 1, 4).

\section{p4-m2 Hypoconulid/Fossette}

The cheek teeth of "Amphilagus" antiquus show a hypoconulid labially connected to each talonid. The simulation of a more worn surface shows that the hypoconulid develops a second connection with the talonid in the labial side, originating a fossette (Figure 11; Animation 1). The sequence of fossette closure is $\mathrm{m} 1-\mathrm{m} 2-\mathrm{p} 4$. The fossettes disappear following the same sequence.

Piezodus also has a hypoconulid labially connected to the talonid of cheek teeth. The formation 

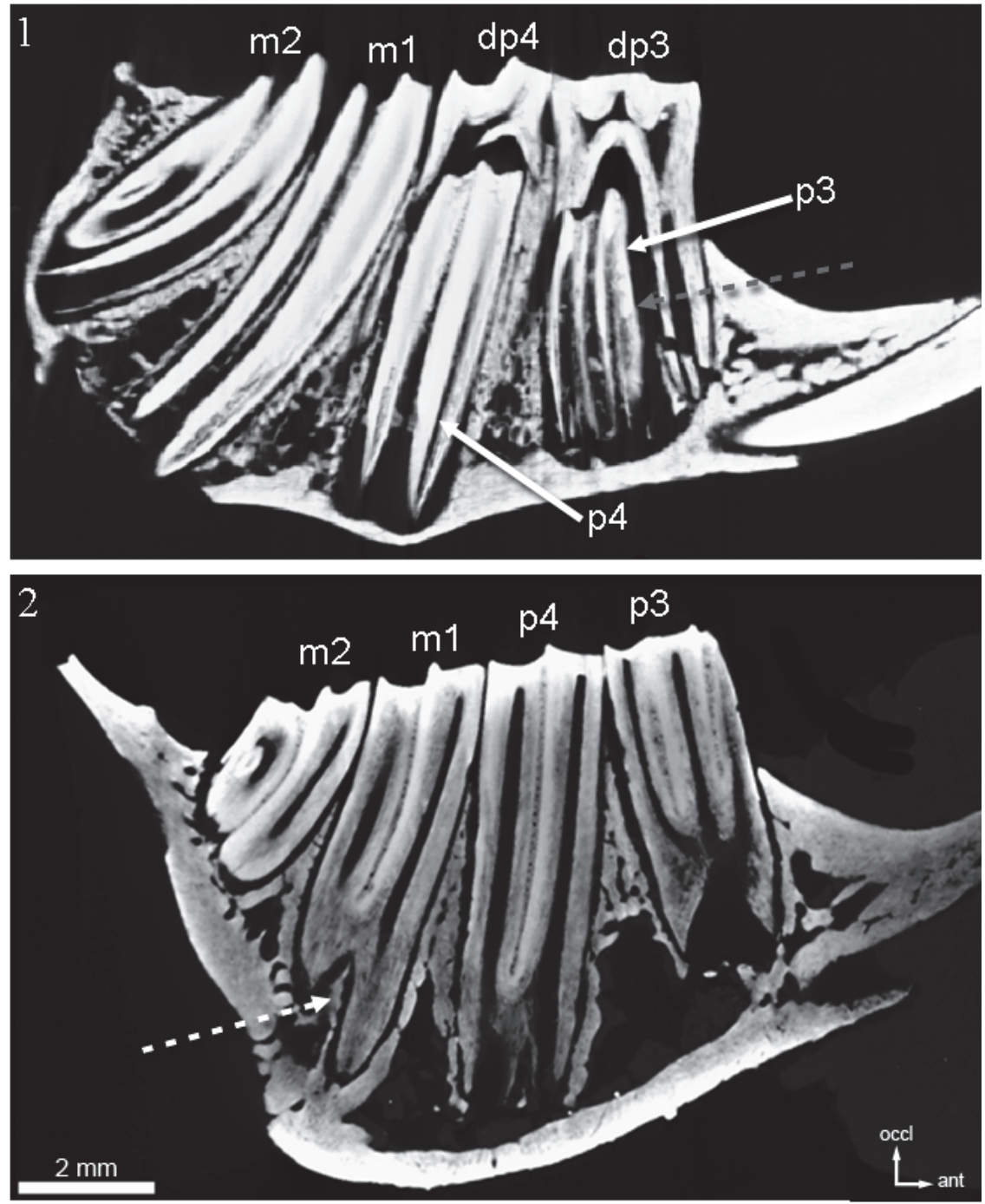

FIGURE 5. Left lower jaw of Piezodus branssatensis virtually sliced along the mesiodistal midline. In the younger specimen (1) we can observe dp3 and dp4 lying upon p3 and p4 (white arrow), and the lack of the anteroconid along the shaft (grey dotted line); the roots are not present. In the older specimen (2) we see the incipient roots (white dotted arrow).

of the fossettes derived from the closure of the hypoconulid follow in Piezodus the sequence: m1p4-m2 (Figure 12; Animation 4), but the disappearance of the fossettes follows like in "Amphilagus" antiquus the sequence m1-m2-p4.

It is known that the hypoconulids are linked to the central part of the talonids pointing lingually in some species of Desmatolagus (e.g., Desmatolagus gobiensis, see Tobien, 1986, p. 228, Figure 11). The investigated specimen of this study only retains a posterior bulk on $\mathrm{m} 2$, and an apparently shallowing up hypoconulid, where no further observations were possible.

No hypoconulids are present in our specimen of Palaeolagus.

\section{DISCUSSION AND CONCLUSIONS}

Our preliminary results test and verify the possibility of a reliable reconstruction of ontogenetic stages in different lagomorph groups by means of an analytical approach, namely the study of Micro CT-scan images that represent virtual slices at different heights of the hypsodont cheek teeth. The ontogenetic reconstruction is important though difficult in lagomorphs (particularly in rooted lagomorphs), but it is necessary in order to exclude overestimations of the number of species in an assemblage. Incorrect evaluations have serious repercussions especially on estimates of palaeobiodiversity, in biochronological applications, and in palaeobiogeographical reconstructions. The results 

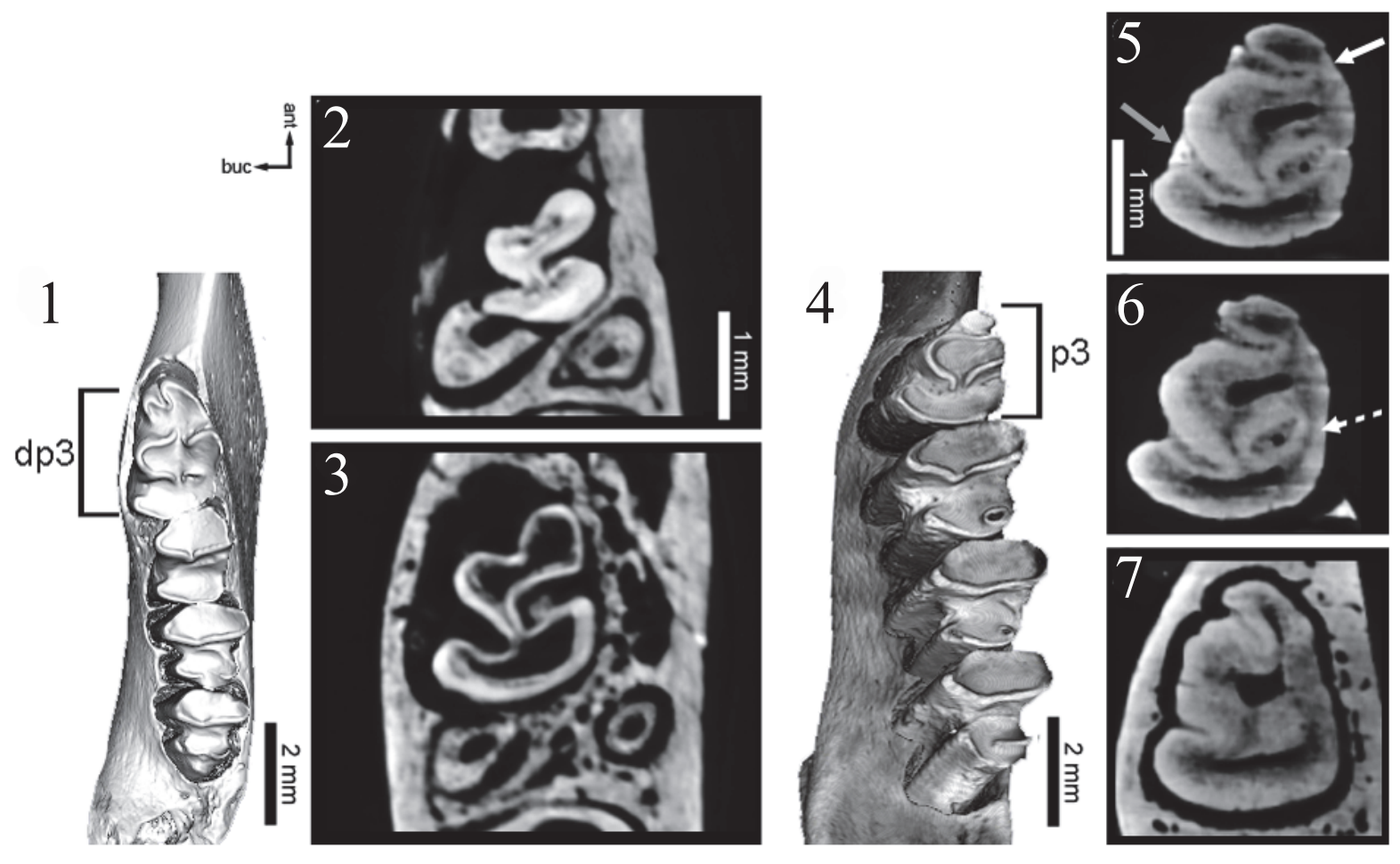

FIGURE 6. Virtual sections of the ontogenetic development of the p3 of Piezodus branssatensis. $(1,4)$ Occlusal surfaces. In the younger specimen the dp3 covers the p3 (1); the unworn p3 has the shape of an hourglass (2) which remains even at maximum stages of wear. The anteroconid (3) does not appear. In the older specimen of Piezodus the anteroconid is already present at the level of the occlusal surface (4), and eventually merges lingually with the trigonid (5) (white arrow); trigonid and talonid merge lingually (6) (dotted white arrow) and the hypoflexid (grey arrow) progressively shallows up (7).
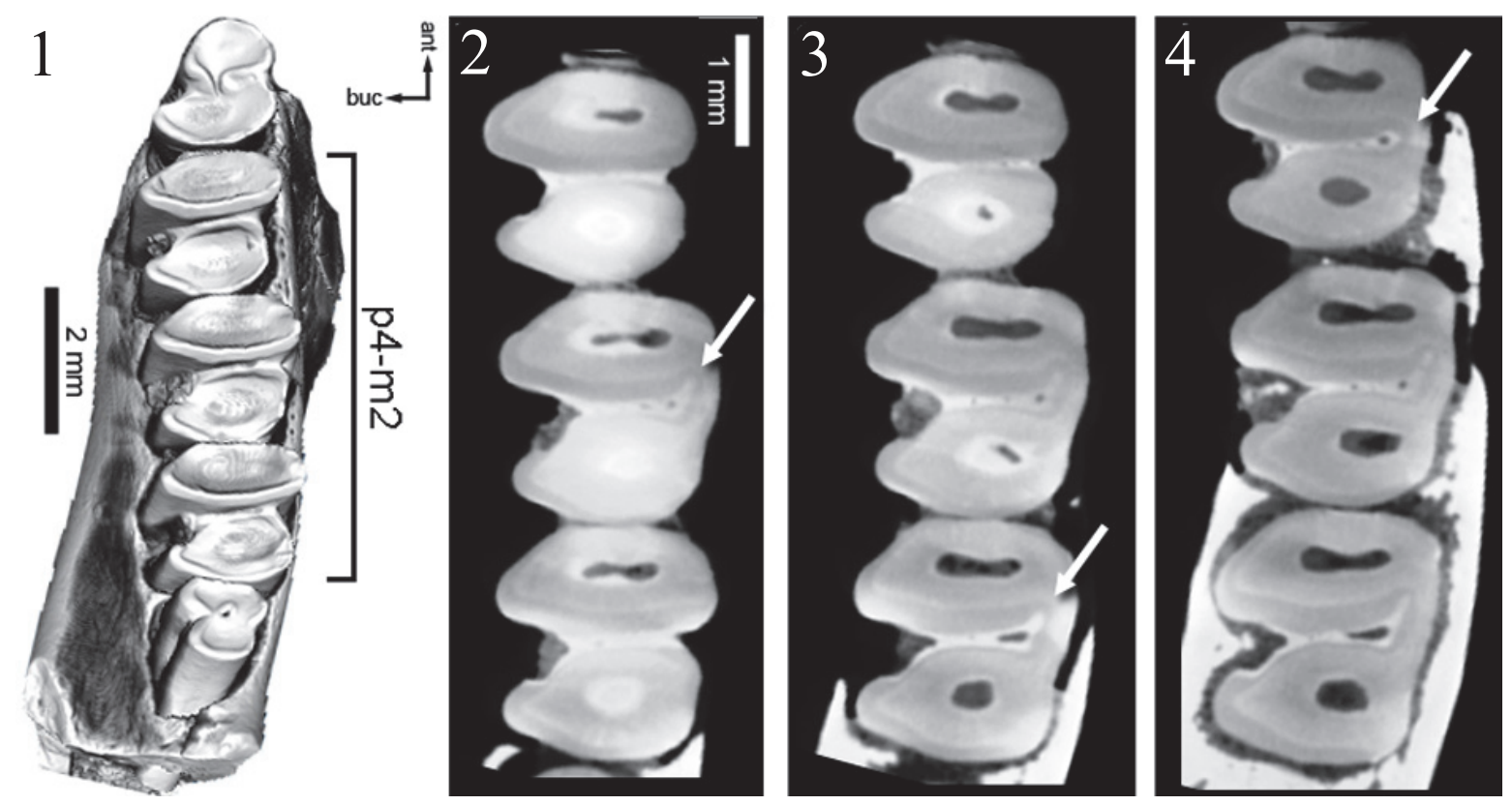

FIGURE 7. Virtual sections of the ontogenetic sequence of the trigonid-talonid connection in Palaeolagus sp. From unconnected trigonids and talonids on the occlusal surface (1) progressive wear produces connections (indicated by the white arrow) in $\mathrm{m} 1$ (2) then in $\mathrm{m} 2$ (3) and at last in p4 (4). 


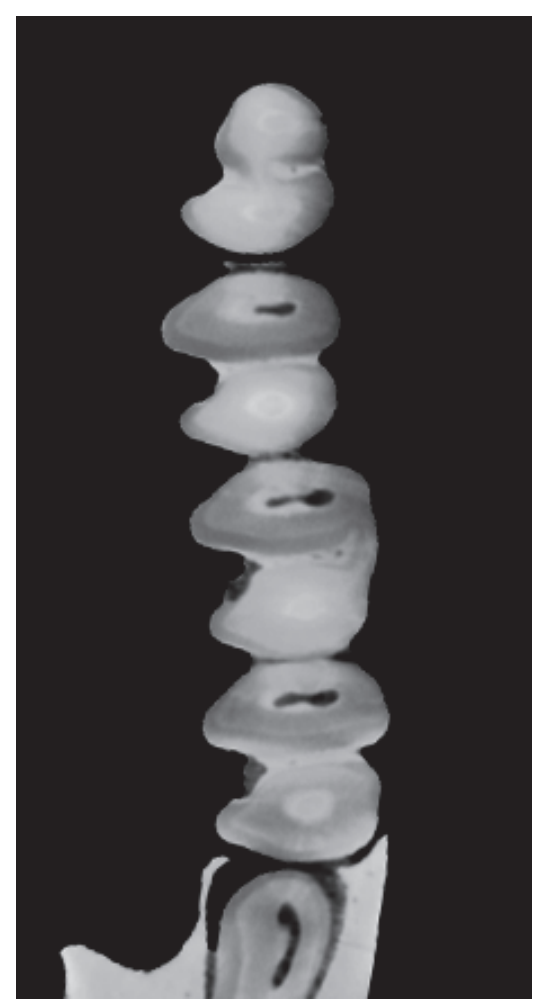

ANIMATION 3. Virtual sectioning of the lower jaw of Palaeolagus sp. shows the ontogenetic development of lower cheek teeth.

palaeo-electronica.org/content/2014/659-tooth-ontogeny-from-ct

of this study demonstrate that an unambiguous ontogenetic pattern can be easily determined in lagomorph lower jaws, revealing different morphological characteristics in the ontogeny of the chosen lagomorph taxa.

\section{Taxonomy}

Micro CT-scan analysis allows us to define the ontogenic development of taxa in several aspects. A correct reconstruction of ontogenetic stages is important for a correct taxonomy, especially for that of Oligocene-Early Miocene rooted lagomorphs, represented by often poorly preserved specimens of sympatric taxa, and whose taxonomy is often controversial.

An important result of our analysis is the fixation of the ontogenetic sequence of "Amphilagus" antiquus from Coderet (at least its adult-senile part). An explanation of the discrepancies with the last senile stages of our specimen with those illustrated in literature (López Martínez, 1989; Tobien, 1974) may be that the sequence of wear in $p 3$ and the sequence of wear of $\mathrm{p} 4-\mathrm{m} 2$ do not follow the same timing in all specimens. An alternative hypothesis may be the presence of two stem lago- morphs at Coderet. Further investigation involving a higher number of specimens is necessary to clarify this issue.

As for lower molariforms (p4-m2) we still cannot determine at which taxonomic level the differences in ontogenetic paths of the studied selected structures can be related (e.g., we do not know if the ontogenetic patterns we individuated can be univocally related to a genus, or to a species, or to a group within a genus, or to a group of directly related species). Some of them are probably related to suprageneric coherences (e.g., the level of trigonid-talonid labial connection in p4-m2), and others are probably discriminant at the genus level (e.g., the fossettes development). Based on the preliminary results presented herein, further studies using Micro-CT images of specimens of different genera of the same group and from the same continent could answer this question and provide reliable taxonomic references.

\section{Phylogeny}

Ontogenetic sequences revealing the chronological appearance of certain structures in lagomorph teeth may reflect phylogenetic affinities or even indicate gaps in our knowledge about this topic.

For example the early central connection of trigonid and talonid in the p3 of Piezodus, that our analysis demonstrated to be already established in unworn specimens, is a new feature in lagomorphs, as no Eurasian species showed this feature before their appearance in MP30 (latest Oligocene), and it would be worthwhile to investigate this further.

Based on our preliminary observations, the appearance of trigonid-talonid labial connection in p4-m2 follows the same scheme in European ochotonids (Piezodus) and Asian and European stem lagomorphs (Desmatolagus and "Amphilagus"). In the North American primitive leporid Palaeolagus the sequence of the trigonid-talonid labial connection follows a completely different pattern. This fact may be an additional indication of an early differentiation of the ancestor of Palaeolagus, from the Asian stock. Indeed the first record of Mytonolagus, the supposed ancestor of Palaeolagus, is at about $\sim 43 \mathrm{Ma}$, close to the first record of Desmatolagus, dating back to $\sim 45 \mathrm{Ma}$ (López Martínez, 2008). CT-scans of Mytonolagus should be compared with those of Palaeolagus to obtain additional clues of their actual affinity, and with those of the early Desmatolagus in order to elucidate if the change in the trigonid-talonid sequence 

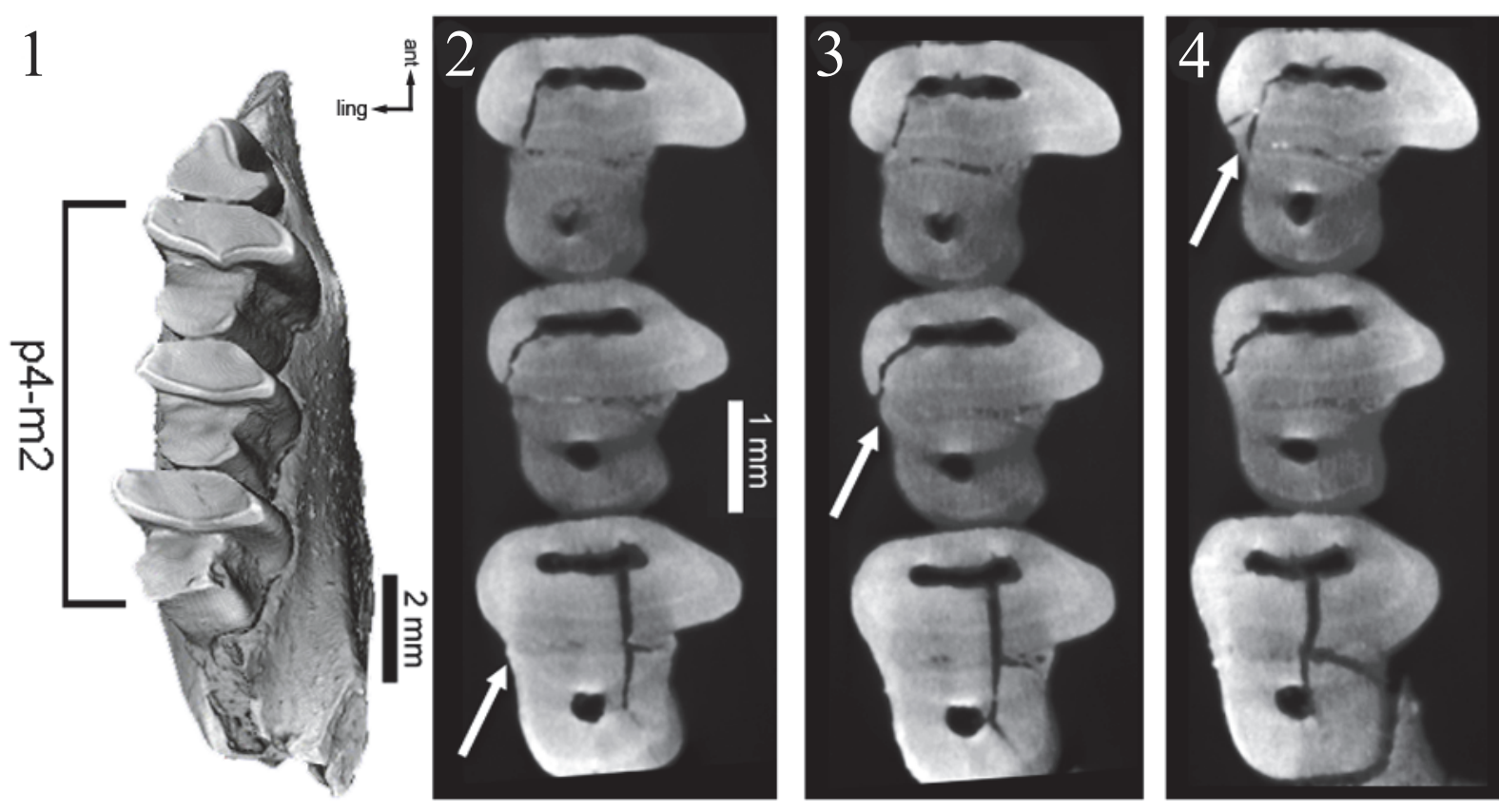

FIGURE 8. Virtual sections of the ontogenetic sequence of the trigonid-talonid connection in Desmatolagus cf. youngi. From unconnected trigonids and talonids on the occlusal surface (1) progressive wear produces connections (indicated by the white arrow) in m2 (2) then in $\mathrm{m} 1$ (3) and at last in p4 (4).

was acquired in North America or earlier in Asia by the Desmatolagus stock who gave origin to North American early lagomorphs.

\section{Perspectives}

This paper provides several potential starting points for future taxonomic and phylogenetic studies based on the observation of the ontogenetic development of some structures of lagomorph lower cheek teeth achieved using MicroCT-scan images. It opens a new research avenue in the study of fossil lagomorphs that is likely to be increasingly prominent in the future. We expect to use this new approach to obtain additional data useful to reconstruct lagomorph inter- and intrageneric relationships and to investigate the differ-
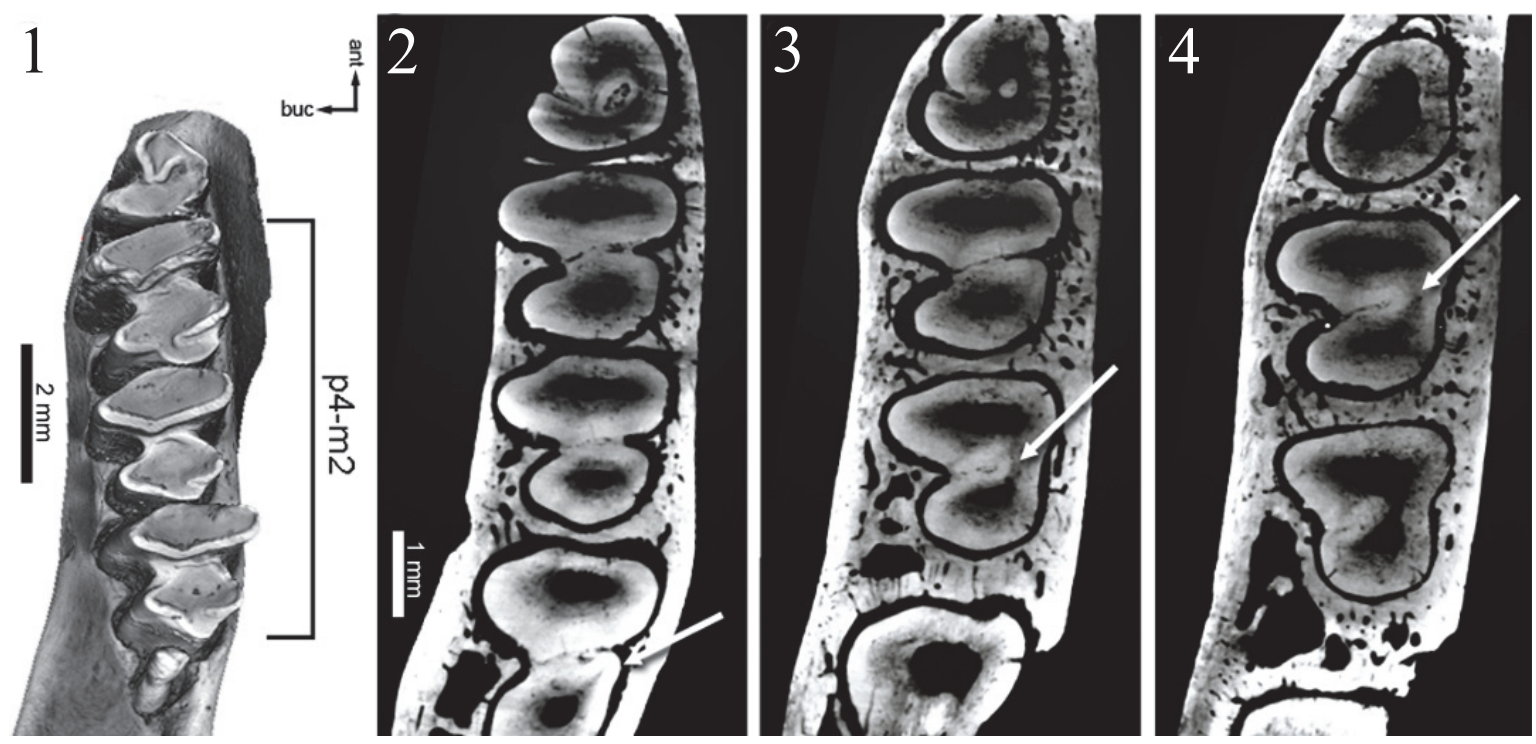

FIGURE 9. Virtual sections of the ontogenetic sequence of the trigonid-talonid connection in "Amphilagus" antiquus. From unconnected trigonids and talonids in the occlusal surface (1) progressive wear starts an incipient connection (indicated by the white arrow) in $\mathrm{m} 2$ (2) then in $\mathrm{m} 1$ (3) and at last in p4 (4). 

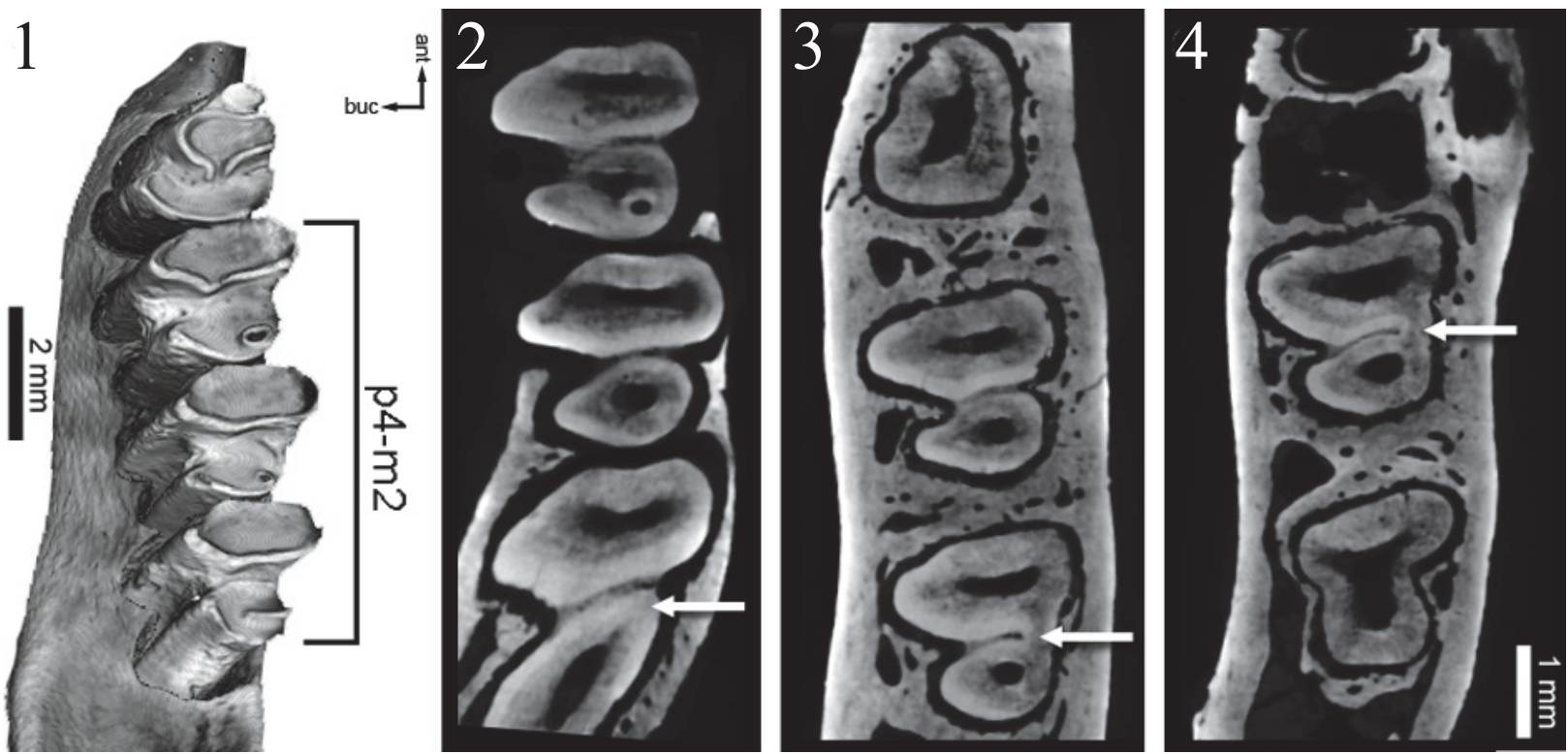

FIGURE 10. Virtual sections of the ontogenetic sequence of the trigonid-talonid connection in Piezodus branssatensis. In the younger specimen trigonid and talonid remain separated even with maximum wear. In the occlusal surface of the older specimen (1) wear starts an incipient connection (white arrow) between trigonids and talonids in m2 (2) then in $\mathrm{m} 1$ (3) and at last in p4 (4).

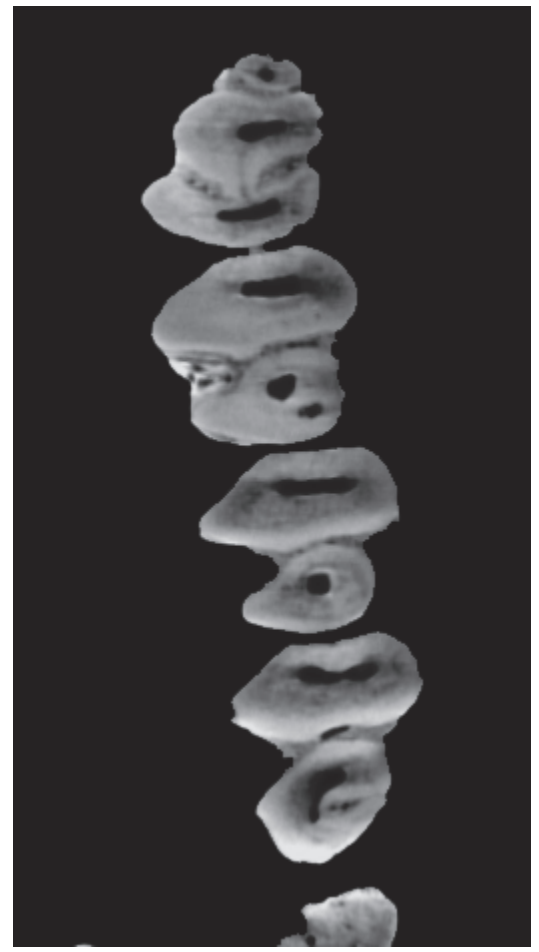

ANIMATION 4. Virtual sectioning of the lower jaw of Piezodus branssatensis (senile specimen) shows the ontogenetic development of lower cheek teeth. palaeo-electronica.org/content/2014/659-tooth-ontogeny-from-ct ences in the patterns of evolution between different lineages and in different continents.

\section{ACKNOWLEDGEMENTS}

We thank P. Göddertz and W. v. Koenigswald from Bonn for providing the 3D X-rays for this study. We are grateful to G. Daxner-Höck and U. Göhlich from Vienna, and again to W. v. Koenigswald for lending fossil material and images in their possession. Two anonymous referees and the editors $\mathrm{J}$. Louys and $\mathrm{H}$. Mallison carefully revised the manuscript and provided valuable suggestions. This work received support by the Spanish Ministerio de Economía y Competitividad (CGL201128681) and has been made in the framework of FWF-Project P-23061-N19: "Impact of Oligo-Miocene climate changes on Mongolian mammals." For researches that resulted important background to this work $\mathrm{C}$. Angelone received support from the SYNTHESYS Project http://www.synthesys.info/, financed by European Community Research Infrastructure Action under the FP6 "Structuring the European Research Area" (AT-TAF-3508). J.A. Schultz is financed by the DFG as a member of the DFG research unit 771 (project D1; MA 1643/16-1) and wants to thank the members of the DFG research unit for discussion. 

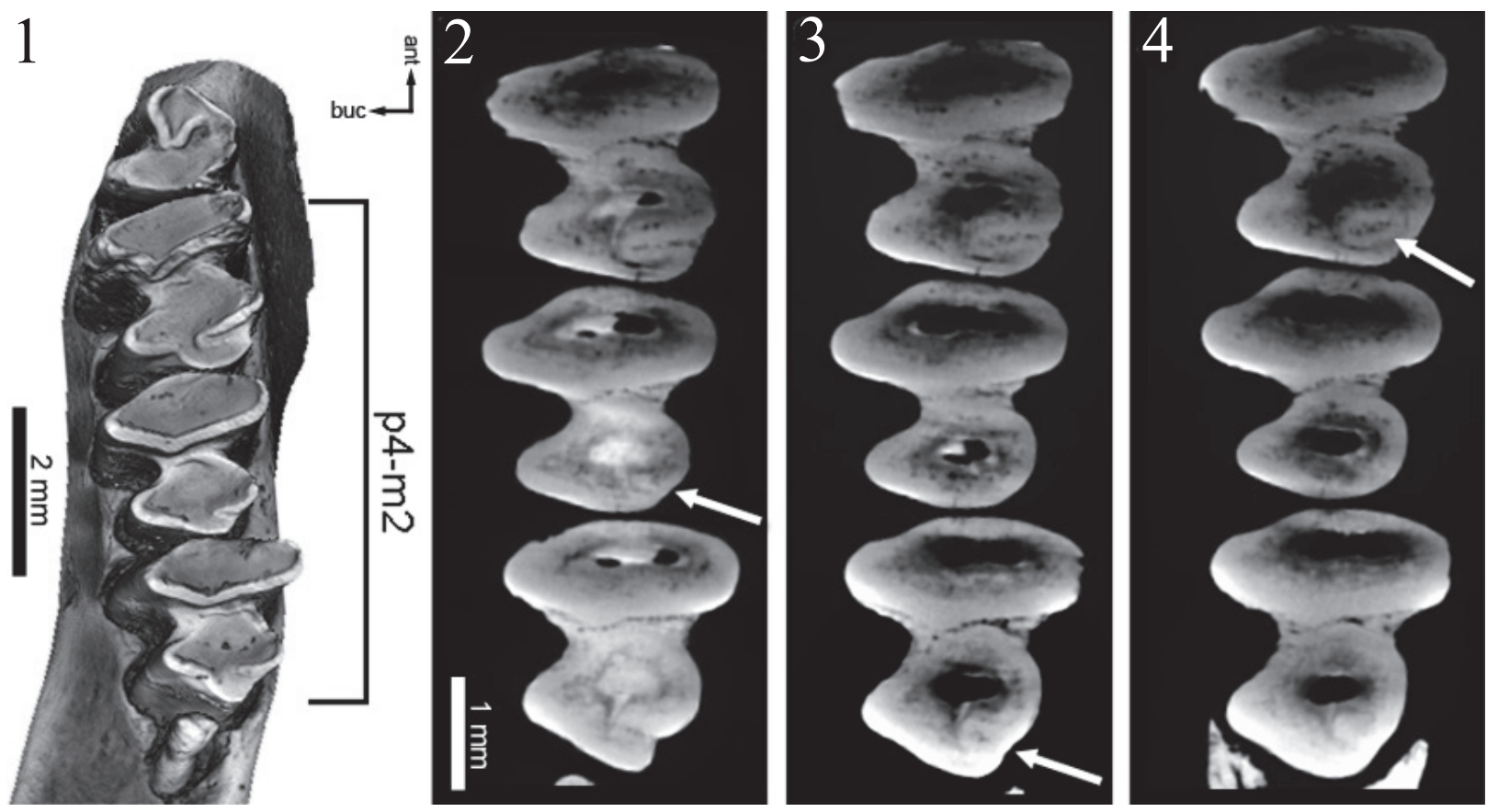

FIGURE 11. Virtual sections of the ontogenetic sequence of hypoconulid/fossettes development in "Amphilagus" antiquus. From lingually directed hypoconulids in the occlusal surface (1) progressive wear develops a fossette (white arrow) in $\mathrm{m} 1$ (2) then in $\mathrm{m} 2$ (3) and at last in p4 (4).
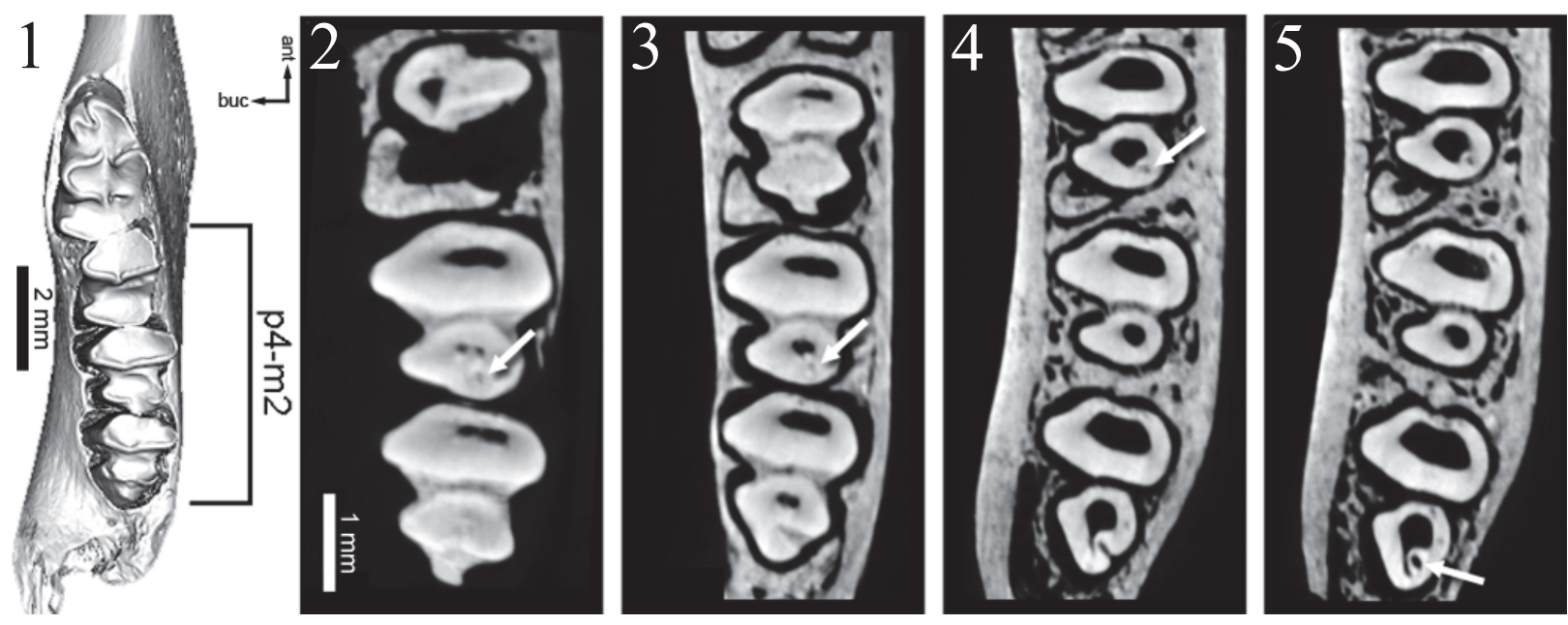

FIGURE 12. Virtual sections of the ontogenetic sequence of hypoconulid/fossettes development in Piezodus branssatensis. In the original occlusal surface only $\mathrm{m} 1$ and $\mathrm{m} 2$ are visible (1); the hypoconulid in $\mathrm{m} 1 \mathrm{forms}$ a fossette in very early stages of wear (2) that rapidly disappears (3); eventually a fossette is formed in p4 (4) and in m2 (5).

\section{REFERENCES}

Álvarez Sierra, M.A., Daams, R., Lacomba, J., López Martínez, N., van der Meulen, A.J., Sesé, C., and de Visser, J. 1990. Palaeontology and biostratigraphy (micromammals) of the continental Oligocene-Miocene deposits of the North-Central Ebro Basin (Huesca, Spain). Scripta Geologica, 94:1-77.
Angelone, C. 2009. Lagomorphs from the Miocene of Sandelzhausen (southern Germany). Paläontologische Zeitschrift, 83:67-75.

Bair, C. 2007. A model of wear in curved mammal teeth: controls on occlusal morphology and the evolution of hypsodonty in lagomorphs. Paleobiology, 33(1):5375. 
Koenigswald, W. v., Anders, U., Engels, S., Schultz, J., and Ruf, I. 2010: Differentiation of mastication in fossil and extant Lagomorpha (Mammalia). Journal of Mammalian Evolution, 17:275-299.

López Martínez, N. 1989. Revisión sistemática y biostratigráfica de los Lagomorpha (Mammalia) del Terciario y Cuaternario de España. Memorias del Museo Paleontológico de la Universidad de Zaragoza 3:1-342.

López Martínez, N. 2008. The lagomorph fossil record and the origin of the European rabbit, p. 27-46. In Alves, P.C., Ferrand, N., and Hackländer K. (eds.), Lagomorph biology: evolution, ecology, and conservation. Springer, Berlin.

Palacios, F.and López Martínez, N. (1980). Morfologia dentaria de las liebres europeas (Lagomorpha, Leporidae). Doñana Acta Vertebrata, 7:61-81.
Tobien, H. 1974. Zur Gebißstruktur, Systematik und Evolution der Genera Amphilagus und Titanomys (Lagomorpha, Mammalia) aus einigen Vorkommen im jüngeren Tertiär Mittel- und Westeuropas. Mainzer geowissenschaftliche Mitteilungen, 3:95-214.

Tobien, H. 1975. Zur Gebißstruktur, Systematik und Evolution der Genera Piezodus, Prolagus und Ptychoprolagus (Lagomorpha, Mammalia) aus einigen Vorkommen im jüngeren Tertiär Mittel- und Westeuropas. Notizblatt des Hessischen Landesamtes für Bodenforschung zu Wiesbaden, 103:103-186.

Tobien, H. 1986. Deciduous teeth of Desmatolagus (Lagomorpha, Mammalia) from the Mongolian Oligocene and of related European taxa. Quartärpaläontologie, 6:223-229. 